\title{
Are We Sure We Fully Understand What an Infodemic Is? A Global Perspective on Infodemiological Problems
}

Alessandro Rovetta*1, Lucia Castaldo ${ }^{2}$

R\&C Research, Bovezzo (BS), Italy

${ }^{*}$ Corresponding author

1. ORCID: 0000-0002-4634-279X

email: rovetta.mresearch@gmail.com

phone number: +393927112808

2. ORCID: 0000-0002-5316-1719

\section{Summary}

Abstract $\quad 2$

Main text $\quad 2$

Infodemiology $\quad 2$

Effects of communications on the lay neutral public 3

The plague of conspiracy hypotheses 4

Problems in scientific communication $\quad 5$

$\begin{array}{ll}\text { Current challenges in scientific publishing and disclosure } & 6\end{array}$

Degrees of evidence and final recommendations $\quad 8$

$\begin{array}{ll}\text { References } & 12\end{array}$ 


\section{Abstract}

As stated by Tedros Adhanom Ghebreyesus, WHO's director-general, we have fought not only the COVID-19 pandemic but also an equally severe infodemic. Although the most striking manifestations of the latter occurred on social networks, some studies show that dismisinformation is significantly influenced by numerous additional factors, both online and offline (i.e., disjoined from the internet). These include social context, age, education, personal knowledge and beliefs, mood, psychological defense mechanisms, media resonance, and how news and information are presented to the public. However, following the evidence in the literature, we also discuss how various incorrect scientific practices related to disclosure, publication, and training can fuel such a phenomenon. In particular, we stress the importance of considering that, in every complex system, all components influence each other. Therefore, if we want to bring down novel infodemics due to future severe crises such as pollution and climate change, we will have to act immediately on all levels. In conclusion, we believe that the construction of resilience to dismisinformation must start with children in schools since the current countermeasures are insufficient to combat a phenomenon that has its roots in personal and collective psychology. Furthermore, we believe that themes such as scientific method and evidence should be at the heart of the university education of a future scientist. Finally, the principle of authority and the obsessive pursuit of prestige must be drastically limited as they undermine the credibility of science.

\section{Main text}

\section{Infodemiology}

Infodemiology was defined by Gunther Eysenbach <<as the science of distribution and determinants of information in an electronic medium, specifically the Internet, or in a population, with the ultimate aim to inform public health and public policy>> [1]. The term was deliberately coined to recall epidemiology. Consequently, infodemic - i.e., "epidemic" of information represents uncontrolled dissemination of information, including false or confusing information, during a disease outbreak [2]. When this dissemination is voluntary and takes place for malicious purposes, we speak of disinformation; otherwise - i.e., when it is unintentional and accidental - we speak of misinformation [3]. Some authors enclose both meanings in the unique term "dismisinformation," while others adopt the more superficial "fake news." The importance of the infodemiological approach has always been known in the scientific community but was established definitively during the current pandemic. In this regard, 132 states have signed an international document to guarantee their commitment to combat the COVID-19 infodemic as this has often resulted in damage of epidemiological and economic nature [2].

In this perspective article, we address infodemiological issues, which, in our opinion, have been largely neglected by a significant fraction of the scientific community. Specifically, we will provide arguments to support the fact that the concept of dismisinformation is broader and more complex than it may seem at first glance. 


\section{Effects of communications on the lay neutral public}

Although infodemics cannot exist without dismisinformation, it is necessary to consider that even correct information - i.e., based on facts and scientific evidence - contributes to its spread. Indeed, the juxtaposition of conflicting information only aggravates the negative influence on the lay public [4]. Such a contrast can arise and grow on two different levels: the dichotomy of reliable and unreliable news (Level 1, e.g., scientific evidence versus dismisinformation) and the scientific debate (Level 2, e.g., differing predictions based on preliminary data). Notable cases occurred during the COVID-19 pandemic. For example, fake news has emerged about the laboratory creation of SARS-CoV-2 as a virological weapon despite the scientific literature supporting the absence of voluntary manipulation [5]. Even more striking was the alleged correlation between 5G and COVID-19 spread [6]. A well-trained scientist understands that such news is fake since the peer-reviewed scientific literature is, in the vast majority of cases, in agreement on the non-existence of such phenomena. However, we must strive to put ourselves in the shoes of an inexperienced person. In particular, on average, a layperson does not have the basis for knowing the concept of "peer review" or "meta-analysis" and can distinguish the reliability of a source only up to a certain point. Let's take a concrete example. I turn on the television and hear about the side effects of COVID-19 vaccines [7]. So I start looking for details on the web, finding reassurance from my health organization [8]. Sometime later, a friend of mine shares a video on Facebook where a doctor (or similar) talks about the severe damage of vaccines, denouncing an international conspiracy. Searching for information on the web, I find an article from the ByoBlu news channel, which confirms the doctor's words; meanwhile, the vaccine debate becomes hot on talk shows [7]. Then, now in a panic, I ask for help from my general practitioner, who turns out to be a convinced no-vax $[9,10]$. Hence, I decide not to vaccinate myself, and I advise my family and friends against vaccines. Unfortunately, this is a realistic scenario, as evidenced by the sources mentioned. Furthermore, this question makes the distinction of a Level 1 from a Level 2 extremely relevant and subtle. In fact, who is to blame for this irrational reaction? To have a reasoned answer, we need to analyze what happened. First of all, we must consider that the influence of the mass media on the population is still extremely high today [11]. Secondly, the conflicting reports, even coming from doctors and scientists, create confusion and diminish trust in the authorities [2]. Rationality gives way to anxiety and fear, increasing the likelihood of assuming harmful behaviors; in this case, not being vaccinated against COVID-19 [2, 12]. Indeed, vaccine hesitancy is fueled by the constant discussion on their side effects due to the cognitive distortion of risk perception [7, 13]. Such a distortion is reinforced by the fact that sensationalistic headlines can create a bias in reading or listening to the news and the emotional impact on risk perception is, on average, much higher than that of a logical argument $[14,15]$. Therefore, the explanations of these phenomena are to be divided between inappropriate communication and personal unpreparedness. While the reasons for writing shocking titles and reporting news with unnecessary emphasis are related to acquiring more audience and click-baiting [16], personal inability to process information rationally does not derive simply or solely from one's willingness not to. In this regard, the WHO has firmly stated that we must build resilience to infodemics [2]. At present, we believe that national school programs are generally inadequate to form the critical and analytical sense necessary to weigh the risk perception based on the available scientific evidence. Specifically, 
we believe people are not guided and educated on how to judge the trustworthiness of a source. Moreover, even teachers and professors are not prepared to deal with such a vast and complicated topic. Therefore, we believe that the first fundamental step in addressing the future infodemic is creating a school program suitable for the formation of resilience to dismisinformation (Point 1). As a matter of fact, changing a psychological or behavioral attitude beyond a specific age group becomes difficult [17-20], which requires acting on the malleable minds of young people to help them become whole and independent people. Similar conclusions on the importance of health education for children and young people were reached by MacDonald et al. [21]. These strategies must be added to what is already being done to combat the infodemic [2].

\section{The plague of conspiracy hypotheses}

Conspiracy thinking originates from questionings of various kinds, including epistemic, existential, and social [22]. There is evidence that these attitudes are the aberration of mechanisms useful for the species' survival, such as pattern recognition, agency detection, threat management, alliance, and dangerous coalitions detection [23]. For instance, the rejection of medical science is caused by complex and unconscious phenomena, including but not limited to illusory truth phenomenon (repeated exposure to falsehood can prime us to accept it implicitly), the availability heuristic (we afford more weight to more readily recalled information, even when this might be misleading), and the fallacy of anecdotal vividness (we tend to react more viscerally to emotive claims than more sober-headed analysis) [24]. Moreover, the Dunning-Kruger effect, which states that incompetents overestimate their knowledge on a particular topic, feeds the conspirationism [25]. This makes communication with these people very difficult as they are excessively prejudicial and do not have the technical means to understand why they are wrong. The press and media coverage of fake news does not help, as confirmatory biases drive conspirationists [7]. In these cases, the implementation of infoveillance and content remotion systems such as those adopted by social platforms could be the only way to limit, at least temporarily, the infodemic on the web [11]. Nonetheless, as discussed in the previous section, conspiracy hypotheses also come from people expected to demonstrate high competence (e.g., doctors and scientists). The most striking case is that of Nobel laureate Luc Montagnier, a staunch supporter of the no-vax movement who has fostered the hypothesis that SARS-CoV-2 was born from a voluntary manipulation of HIV [26, 27]. Such incidents have been far from isolated, as evidenced by many professors, doctors, and nurses demonstrating skepticism and unfounded views on vaccines [9, 10, 28]. In particular, Paris et al. highlighted the devastating impact of media communication about vaccine side effects on the class of healthcare workers [28]. At the same time, Heyerdahl et al. showed that fear of peer judgment prompted many healthcare professionals not to express their doubts about COVID-19 vaccination [29]. This evidence exhibits that not even these people's scientific training has been sufficient to manage the infodemic. Furthermore, conspiracy and dread often mix in a murky sea that makes them almost indistinguishable. Therefore, we believe that scientific training should focus more on adopting the scientific method and analyzing sources' reliability (Point 2). Specifically, a science graduate should master the concept of "degrees of evidence" (e.g., pre-print paper vs. peer-reviewed original article or peer-reviewed original article vs. 
peer-reviewed meta-analysis). On this point, we also believe it essential that the principle of authority be minimized: the conviction of being an expert in the sector must not induce us to think that we can ignore the most recent scientific evidence. A scientist is a real scientist only if he is constantly willing to question what he knows based on the most updated literature.

\section{Problems in scientific communication}

Beyond the glaring errors of the press and conspiratorial characters, including scientists, we must ask ourselves: has the communication from the scientific community been adequate? On January 14, 2020, WHO wrote on the official Twitter account: <<Preliminary investigations conducted by the Chinese authorities have found no clear evidence of human-to-human transmission of the novel \#coronavirus (2019-nCoV) [...] >> [30]. This statement means that, at the moment, the scientific community does not know if the novel coronavirus 2019-nCoV can be transmitted from human to human. The subsequent day, Dr. Maria Van Kerkhove stated in a press conference: <<From the information that we have it is possible that there is limited human-to-human transmission, potentially among families, but it is very clear right now that we have no sustained human-to-human transmission >> [31, 32]. The first part of the statement is very cautious, as it is weighted on expressions like "From the information that we have" and "it is possible." On the contrary, the second sentence alludes to an implausible possibility, that is, that there is clear evidence to affirm that the virus is not transmitted easily from person to person. In fact, this affirmation was soon denied not only by robust evidence of transmission from symptomatic infected but also from presymptomatics and asymptomatics [33-35]. Information channels with a large audience shared this news adding further inaccuracies. For example, Reuters published two articles with the same title five minutes apart. In the first, the opening sentence used the verb "has [limited transmission]" [36], while in the second (the "US" version), the wording "may have" was adopted [37]. In summary, we have confusing, slightly inaccurate, and covertly contradictory information presented to an inexperienced audience. Even worse is the media debate that arose before the pandemic outbreak in Europe. For example, in Italy, scientists provided diametrically opposed opinions on the severity of COVID-19, breaking public opinion in half $[7,11]$. This contributed to the emergence of serious protests when the implementation of lockdowns was requested, which proved to be a fundamental tool in cutting down the number of cases and saving millions of lives [38]. In such delicate times, words are just boulders and must be chosen carefully. Indeed, communication errors of this type can provide material for conspiracy hypotheses and confuse the public trying to orient themselves within a new dramatic and unusual situation. Beyond the mistakes of the press for which they are not responsible, scientists have a moral obligation to predict the public reaction to certain circumstances as they possess an additional intellectual tool, i.e., the scientific method. When it is necessary to communicate sensitive information, it would be advisable to write the texts or at least the essential passages of the latter to ensure the greatest possible clarity and precision. Furthermore, when consulted, doctors and professors must behave scientifically, that is, base their claims on the degree of evidence available in the literature (Point 3). In this respect, we would like to share the experience and thoughts of one of the authors (AR). AR: <<On several occasions during COVID-19, I have had discussions with some scientists who were well-known faces of the web and Italian television. The latter's nature 
concerned an aspect that I consider of absolute communicative importance: the scientific validity of public statements. For example, many argued COVID-19-related opinions on their Facebook public profiles based on a single pre-print without specifying that those results were not peer-reviewed nor confirmed by other literature. One of them even replied that this clarification was unnecessary since he was a peer-reviewer, as if a single reviewer could replace the entire peer-review process that includes two or more reviewers - depending on the topic's relevance - and an editor's final judgment. What surprises me is the arrogance of people who think they can be above the scientific method and community because they have an academic title or role. All this while we have had direct proof that even Nobel laureates can assert dangerous unscientific nonsense. What lesson is being taught to the public by acting this way? Such an excessive usage of the principle of authority distances us from facts and credible communication and urges the public to give importance to the individual rather than the available evidence.>>

\section{Current challenges in scientific publishing and disclosure}

Returning to the previous section, we ask ourselves: what is the reason that prompts scientists to share comments on pre-prints or other forms of non-peer-reviewed literature? During the COVID-19 pandemic, rapid and timely interventions were significant public health challenges [39]. Since COVID-19 depends on many factors and comorbidities and the variants of concern can substantially change its behavior [40-42], having reliable updated data in short times is an essential aspect of containing outbreaks. Unfortunately, the peer review and publication processes are inadequately slow to face a health crisis properly. Huisman et al. found that only $13-16 \%$ of papers covering medicine, natural sciences, and public health were accepted within one month, and the average acceptance time ranged from 12 to 14 weeks [43]. In our experience as reviewers and authors for over 50 scientific journals during COVID-19, we encountered very long publication times, even for articles with a high scientific impact (e.g., side effects of COVID-19 vaccines). Therefore, we understand and agree on the need to comment on preliminary findings as long as it is openly stated that these results are uncertain and the meaning of "pre-print" is clearly explained to the public. Furthermore, national and supranational agencies such as the Centers for Disease Control and Prevention (CDC), European Medicines Agency (EMA), Food and Drug Administration (FDA), and World Health Organization (WHO) are constant sources of up-to-date internally reviewed data and can be consulted to obtain credible and calibrated news on the available evidence. Finally, we firmly believe that peer-reviews should give absolute priority to Methods and Results over other sections, and journals should report methodological acceptance of the manuscript publicly. By doing so, researchers in the field - who are unlikely to need the Introduction and Discussion sections to understand and contextualize the paper - could receive new data more promptly. We must remember that science, especially medicine, saves lives. Delaying the publication of a manuscript for aesthetics, layout, or sections not essential for its reproducibility is just an unjustifiable academic caprice. Unfortunately, as things stand, a peer reviewer is required to report these aspects, and journals should be the ones to change their editorial policy. 
Alongside this, the scientific community has to deal with internal situations. The first we want to discuss is predatory publication. Predatory journals offer rapid publication times at meager costs, making them very attractive to independent researchers who do not have funds available. However, these apparent benefits arise from poor or bogus peer-review processes [44]. Hence, the researchers identified various strategies to combat this phenomenon, including creating lists of predatory scientific journals and publishers and bibliographic abstracting and indexing [45, 46]. Nonetheless, the inclusion criteria in predatory blacklists have always been the subject of criticisms and controversies, and predatory publication has managed to slip into prestigious repositories like PubMed $[47,48]$. Ergo, there is no foolproof way but only general indications to recognize and avoid predatory publishers. The predatory phenomenon could be provoked and sustained by the success of the open access publishing method and/or the excessive editorial costs of renowned journals $[49,50]$. Nevertheless, even the rush to publish their results can push an author to choose alternative routes to standard publication. The second issue we want to discuss concerns the scientific role of peer review. Specifically, peer-review is a fundamental procedure to ensure the accuracy of manuscripts published in scientific journals [51]. The independent judgment of two or more expert scientists not involved in the study examined and without conflicts of interest is a first step to skim the literature from gross errors. At the same time, a single article with new results is always a low degree of evidence until other studies confirm its findings. In fact, peer-review still presents several flaws, including a possible low agreement between the referees [52-54]. In confirmation of this, it is not surprising to find numerous withdrawn articles [55]. Therefore, peer-review is not and cannot be the final judgment on a scientific paper. Based on these premises, Dr. John Adler has proposed a quick review method that also includes a post-publication review [56]. Yet this approach was not unanimously accepted by the scientific community. Checco et al. recently proposed (semi) automated artificial intelligence peer review systems capable of assisting the reviewer and improving the review quality, but the authors conclude that there are still concerns to be settled [57]. The third issue we want to highlight regards the conflict of interest of journal publications and the unpaid contribution of peer reviewers. Peer review is a time-consuming and challenging process. Some researchers believe paying reviewers could facilitate shoddy reviews with the sole scope of getting the money reward [58]. In this regard, the authors of this paper - and many other scientists [58] - consider this statement to be simply false for various reasons. Reason A: Reviewers are selected by editors responsible for judging their reliability. Reason $\mathrm{B}$ : The same criticism can also be raised for unpaid reviews as a referee could carry out hasty reports to obtain easy certification for personal prestige and curriculum. Reason C: Pay reviewers would transform peer-review into a real job with merit-based selection. In this regard, getting paid to conduct a review could increase competition for top-notch reviews. Moreover, we believe that it would be far more rewarding and fair for reviewers to have their work generate income. In our experience, a concrete example is that of JMIR Publications: if the editor evaluates the review of sufficient quality, a reviewer can earn up to 100 dollars to spend to publish in one of their journals [59]. Even if it is something very distant from a real waged job, this can be a first step in proving that the model is perfectly sustainable. Beyond that, we consider the association "paid reviewer - compromised review" hypocritical within the current editorial context. Indeed, the paid publication itself is basically a conflict of interest since journals only receive money if the articles are published. For instance, the standard policy of publishers provides that a paper retraction 
does not involve the return of the article process charge to the authors, i.e., editors may be motivated to publish regardless of the quality of the manuscript [60]. Notwithstanding that, forcing the public to pay to read is not an acceptable solution if the goal is to keep the scientific community and the population updated on the latest evidence. The question is: what to do then? The open-access model is now widespread, and there is sufficient evidence that paying reviewers does not compromise the scientific quality of manuscripts. Since science continues to work, we believe that this is the right way to follow, with the awareness that the final judgment comes from the scientific community and not from the peer review. The fourth critical aspect concerns the search for scientific prestige. Many authors are convinced that metrics such as impact factor and number of citations are quality indices, while a vast scientific literature demonstrates that such indices are unreliable and can even be misleading [61]. Two of the main reasons are that the impact factor is primarily influenced by outliers (i.e., very few papers with very high citations), and the citations could reflect more the media success of an article than its quality (i.e., more in-depth articles may not be known). In addition, it is necessary to consider why a paper was cited (e.g., many citations concern introductory outline aspects). Just as the first duty of peer reviewers is not to be influenced by the prestige of the authors, the first duty of researchers is not to be affected by the reputation of journals when asked to evaluate the scientific content of a paper. As proof of this, numerous pre-prints have received thousands of positive citations inherent to the methodology adopted (e.g., [62]). But the obsessive pursuit of prestige can also plague publishers. For instance, editorial reluctance to publish negative or null results can strongly bias literature $[63,64]$. Regarding all this, we support the healthy desire to be deemed great scientists and receive well-deserved gratifications as long as these do not lead to scientific discrimination and bias. But, considering the above evidence, part of the scientific community seems more interested in self-achievements rather than facts, and we need to change this. The fifth and final point concerns the secrecy of peer reviews. On January 16 , 2020, Dr. Thijs Kuiken was contacted by "The Lancet" journal to review a paper within 48 hours [65]. The research showed strong evidence that SARS-CoV-2 was transmissible between humans, but the reviewer was expected to keep silent to protect the integrity of the evaluation and the authors' and journal's rights. Nonetheless, Dr. Kuiken faced this ethical dilemma with courage and conscientiousness and found a way to communicate the data to the WHO quickly. This episode testifies that the omission of essential public health information must be viewed as full-fledged disinformation. We stress that rapid medical evidence can save human lives and must be prioritized above everything else, especially during health crises. Failure to immediately communicate novel results to the authorities worldwide is serious wrongdoing, and we must avoid it in the proximal future. Therefore, a standard procedure to deal with these exceptional situations must be designed and implemented as soon as possible.

\section{Degrees of evidence and final recommendations}

The concepts of degree (or level) of evidence have long been addressed in the literature and differ by health discipline [66]. Various changes have been made over time, attempting to improve the standard classifications [67]. Despite this, as shown in the previous sections, this

element is culpably left out in most public statements. The public should be educated on the 
concept of the degree of evidence whenever a result is presented to it. Doing so would limit the damage of conflicting information since not all information would have the same reliability anymore. Therefore, we recommend that health agencies establish a standard classification of degrees of evidence that can be adopted internationally for each discipline by each practitioner. In the meantime, all medical professionals should adopt and specify the scale they deem most appropriate before expressing public statements on sensitive topics. As regards other types of information (e.g., facts and fake news checks), we propose the following scale of degrees of evidence.

F. Regardless of their authority, personal opinions must be ranked with the lowest degree of evidence. This is necessary to ensure consistency in class attribution. In particular, the authority principle must be minimized to prevent unjustified claims (e.g., Montagnier) from sowing doubt, fear, and false information. Therefore, all conclusions that have not been moderated or peer-reviewed fall into this category.

E. Preprints moderation avoids the circulation of very serious fake news in the scientific world, but it is not comparable to a peer-review process. Indeed, a large number of preprints fueling conspiracy theories and unjustified assumptions have been unearthed [68]. Therefore, although the probability of finding infodemics is lower than the previous category, moderated preprints do not represent sufficient evidence to make scientific and especially medical claims.

D. This category encompasses academic journals not yet indexed in recognized databases (e.g., due to their novelty) and not listed among predatory journals (e.g., Beall's List). The degree of evidence is sufficient to expose assessments to the public based on the latter, provided that it is specified that these are premature analyzes. Furthermore, inclusion in this class implies that an extensive literature search has been done, ascertaining the absence of known opposite results. If the number of articles reporting contrary findings is comparable, then the scientist is required to express a personal judgment (e.g., comparing the validity of the two studies on their scope); in this case, the quality of the evidence is class $\mathrm{E}$. If the number of articles supporting contrary results is significantly greater, then the scientist is required to make a personal judgment and present the quality of the evidence as class F.

C. The criteria of point $D$ apply, but the probability of disseminating infodemic material further decreases thanks to bibliographic indexing.

B. The criteria of point $\mathrm{C}$ apply, but there must be at least three agreeing articles. Evidence proposed by recognized health agencies (e.g., EMA, CDC, WHO) can fall into this category.

A. The criteria in point B apply, but the articles must be systematic meta-analyzes and/or reviews. Evidence proposed by recognized health agencies (e.g., EMA, CDC, WHO) can fall into this category.

We stress that this scale is indicative and needs to be further elaborated by the scientific community, including all the particular cases that have escaped us or improving the basic 
setting. However, we believe it can serve as a general guideline, showing a possible way forward to limit the infodemic drastically. Indeed, the simple fact of specifying the sources and the type of evidence proposed can give the public an idea of the news relevance and weight. A summary is proposed in Table 1.

\begin{tabular}{|l|l|l|l|}
\hline $\begin{array}{l}\text { Class } \\
\text { Quality }\end{array}$ & $\begin{array}{l}\text { Color-related } \\
\text { name }\end{array}$ & Complete name & Evaluation description \\
\hline F & Red & $\begin{array}{l}\text { Opinion } \\
\text { (very poor validity) }\end{array}$ & $\begin{array}{l}\text { Based on raw data, personal experience, or } \\
\text { pre-print not deposited on accredited preprint } \\
\text { repositories. }\end{array}$ \\
\hline D & Orange & $\begin{array}{l}\text { Indexed novel } \\
\text { preprint } \\
\text { (poor validity) }\end{array}$ & $\begin{array}{l}\text { Based on a new preprint deposited on one or } \\
\text { more accredited preprint repositories. }\end{array}$ \\
\hline C & Yellow & $\begin{array}{l}\text { Unindexed new } \\
\text { article } \\
\text { (uncertain validity) }\end{array}$ & $\begin{array}{l}\text { Based on a new article not deposited on } \\
\text { accredited article repositories. Known predatory } \\
\text { journals are excluded. }\end{array}$ \\
\hline B & White & $\begin{array}{l}\text { Indexed article } \\
\text { (fair validity) }\end{array}$ & $\begin{array}{l}\text { Based on one or two articles deposited on one or } \\
\text { more accredited article repositories or affirmed } \\
\text { anti-hoax non-government websites. }\end{array}$ \\
\hline A & Azure & $\begin{array}{l}\text { Evidence } \\
\text { (good validity) }\end{array}$ & $\begin{array}{l}\text { Based on three } \text { or more concording articles or } \\
\text { highly cited preprints deposited on accredited } \\
\text { article repositories or accredited grey literature. }\end{array}$ \\
\hline
\end{tabular}

Table 1. Scientific communication quality classes. The marked line highlights the sufficiency threshold. ${ }^{1}$ This number may change depending on the importance of the evidence (e.g., much more evidence may be required on drug-related information). *Unless a large number of concordant positive reviews are reached by the scientific community. 


\section{References}

[1] Eysenbach G. Infodemiology and infoveillance: framework for an emerging set of public health informatics methods to analyze search, communication and publication behavior on the Internet. J Med Internet Res. 2009 Mar 27;11(1):e11. doi: 10.2196/jmir.1157. PMID: 19329408; PMCID: PMC2762766.

[2] World Health Organization (WHO). Infodemic. URL: https://www.who.int/health-topics/infodemic (accessed January 7, 2022).

[3] Wang Y, McKee M, Torbica A, Stuckler D. Systematic Literature Review on the Spread of Health-related Misinformation on Social Media. Soc Sci Med. 2019 Nov;240:112552. doi: 10.1016/j.socscimed.2019.112552. Epub 2019 Sep 18. PMID: 31561111; PMCID: PMC7117034.

[4] Nagler RH, Yzer MC, Rothman AJ. Effects of Media Exposure to Conflicting Information About Mammography: Results From a Population-based Survey Experiment. Ann Behav Med. 2019 Aug 29;53(10):896-908. doi: 10.1093/abm/kay098. PMID: 30596830; PMCID: PMC6735717.

[5] Maxmen A, Mallapaty S. The COVID lab-leak hypothesis: what scientists do and don't know. Nature. 2021 Jun;594(7863):313-315. doi: 10.1038/d41586-021-01529-3. PMID: 34108722.

[6] Ahmed W, Vidal-Alaball J, Downing J, López Seguí F. COVID-19 and the 5G Conspiracy Theory: Social Network Analysis of Twitter Data. J Med Internet Res. 2020 May 6;22(5):e19458. doi: 10.2196/19458. PMID: 32352383; PMCID: PMC7205032.

[7] Rovetta A. The Impact of COVID-19 on Conspiracy Hypotheses and Risk Perception in Italy: Infodemiological Survey Study Using Google Trends. JMIR Infodemiology. 2021 Aug 6;1(1):e29929. doi: 10.2196/29929. PMID: 34447925; PMCID: PMC8363126.

[8] Ministero della Salute. Vaccini anti Covid-19 - I vaccini sono sicuri?. URL: https://www.salute.gov.it/portale/nuovocoronavirus/dettaglioFaqNuovoCoronavirus.jsp?id=255

[Accessed January 7, 2022].

[9] Le Marechal M, Fressard L, Agrinier N, Verger P, Pulcini C. General practitioners' perceptions of vaccination controversies: a French nationwide cross-sectional study. Clin Microbiol Infect. 2018 Aug;24(8):858-864. doi: 10.1016/j.cmi.2017.10.021. Epub 2017 Nov 24. PMID: 29104170.

[10] Quotidiano Sanità. Aggressione di medici No-Vax durante assemblea Ordine di Roma. Magi "Le contrapposizioni vanno evitate. Valuteremo i vari comportamenti". URL: https://www.quotidianosanita.it/lavoro-e-professioni/articolo.php?articolo id=101041 [Accessed January 7,2022$]$. 
[11] Rovetta A, Castaldo L. Influence of Mass Media on Italian Web Users During the COVID-19 Pandemic: Infodemiological Analysis. JMIRx Med. 2021 Oct 18;2(4):e32233. doi: 10.2196/32233. PMID: 34842858; PMCID: PMC8601032.

[12] Troiano G, Nardi A. Vaccine hesitancy in the era of COVID-19. Public Health. 2021 May;194:245-251. doi: 10.1016/j.puhe.2021.02.025. Epub 2021 Mar 4. PMID: 33965796; PMCID: PMC7931735.

[13] Tversky A, Kahneman D. A heuristic for judging frequency and probability. Cogn Psychol. 1973;5(2):207-232. doi: 10.1016/0010-0285(73)90033-9.

[14] Ecker UK, Lewandowsky S, Chang EP, Pillai R. The effects of subtle misinformation in news headlines. J Exp Psychol Appl. 2014 Dec;20(4):323-35. doi: 10.1037/xap0000028. Epub 2014 Oct 27. PMID: 25347407.

[15] Megías A, Cándido A, Maldonado A, Catena A. Neural correlates of risk perception as a function of risk level: An approach to the study of risk through a daily life task. Neuropsychologia. 2018 Oct;119:464-473. doi: 10.1016/j.neuropsychologia.2018.09.012. Epub 2018 Sep 20. PMID: 30244003.

[16] Bolton DM, Yaxley J. Fake news and clickbait - natural enemies of evidence-based medicine. BJU Int. 2017 May;119 Suppl 5:8-9. doi: 10.1111/bju.13883. PMID: 28544296.

[17] Xie B, Watkins I, Golbeck J, Huang M. Understanding and Changing Older Adults' Perceptions and Learning of Social Media. Educ Gerontol. 2012 Apr 1;38(4):282-296. doi: 10.1080/03601277.2010.544580. Epub 2012 Jan 11. PMID: 22639483; PMCID: PMC3358790.

[18] Vaportzis E, Clausen MG, Gow AJ. Older Adults Perceptions of Technology and Barriers to Interacting with Tablet Computers: A Focus Group Study. Front Psychol. 2017 Oct 4;8:1687. doi: 10.3389/fpsyg.2017.01687. PMID: 29071004; PMCID: PMC5649151.

[19] Cookman CA. Older people and attachment to things, places, pets, and ideas. Image J Nurs Sch. 1996 Fall;28(3):227-31. doi: 10.1111/j.1547-5069.1996.tb00356.x. PMID: 8854544.

[20] Matamales M, Skrbis Z, Hatch RJ, Balleine BW, Götz J, Bertran-Gonzalez J. Aging-Related Dysfunction of Striatal Cholinergic Interneurons Produces Conflict in Action Selection. Neuron. 2016 Apr 20;90(2):362-73. doi: 10.1016/j.neuron.2016.03.006. PMID: 27100198.

[21] MacDonald NE, Dubé E. Addressing vaccine hesitancy in immunization programs, clinics and practices. Paediatr Child Health. 2018 Dec;23(8):559-560. doi: 10.1093/pch/pxy131. Epub 2018 Nov 19. PMID: 31043843; PMCID: PMC6241901. 
[22] Douglas KM, Sutton RM, Cichocka A. The Psychology of Conspiracy Theories. Curr Dir Psychol Sci. 2017 Dec;26(6):538-542. doi: 10.1177/0963721417718261. Epub 2017 Dec 7. PMID: 29276345; PMCID: PMC5724570.

[23] van Prooijen JW, van Vugt M. Conspiracy Theories: Evolved Functions and Psychological Mechanisms. Perspect Psychol Sci. 2018 Nov;13(6):770-788. doi: 10.1177/1745691618774270. Epub 2018 Sep 19. PMID: 30231213; PMCID: PMC6238178.

[24] Grimes DR. Medical disinformation and the unviable nature of COVID-19 conspiracy theories. PLoS One. 2021 Mar 12;16(3):e0245900. doi: 10.1371/journal.pone.0245900. PMID: 33711025; PMCID: PMC7954317.

[25] Gonçalves-Sá J. In the fight against the new coronavirus outbreak, we must also struggle with human bias. Nat Med. 2020 Mar;26(3):305. doi: 10.1038/s41591-020-0802-y. PMID: 32152585; PMCID: PMC7073250.

[26] Arif N, Al-Jefri M, Bizzi IH, Perano GB, Goldman M, Haq I, Chua KL, Mengozzi M, Neunez M, Smith H, Ghezzi P. Fake News or Weak Science? Visibility and Characterization of Antivaccine Webpages Returned by Google in Different Languages and Countries. Front Immunol. 2018 Jun 5;9:1215. doi: 10.3389/fimmu.2018.01215. Erratum in: Front Immunol. 2019 Oct 01;10:2252. PMID: 29922286; PMCID: PMC5996113.

[27] Sallard E, Halloy J, Casane D, Decroly E, van Helden J. Tracing the origins of SARS-COV-2 in coronavirus phylogenies: a review. Environ Chem Lett. 2021 Feb 4:1-17. doi: 10.1007/s10311-020-01151-1. Epub ahead of print. PMID: 33558807; PMCID: PMC7859469.

[28] Paris C, Bénézit F, Geslin M, Polard E, Baldeyrou M, Turmel V, Tadié É, Garlantezec R, Tattevin P. COVID-19 vaccine hesitancy among healthcare workers. Infect Dis Now. 2021 Aug;51(5):484-487. doi: 10.1016/j.idnow.2021.04.001. Epub 2021 May 5. PMID: 33964486; PMCID: PMC8098031.

[29] Heyerdahl LW, Dielen S, Nguyen T, Van Riet C, Kattumana T, Simas C, Vandaele N, Vandamme AM, Vandermeulen C, Giles-Vernick T, Larson H, Grietens KP, Gryseels C. Doubt at the core: Unspoken vaccine hesitancy among healthcare workers. Lancet Reg Health Eur. 2022 Jan;12:100289. doi: 10.1016/j.lanepe.2021.100289. Epub 2021 Dec 14. PMID: 34927116; PMCID: PMC8668386.

[30] World Health Organization (WHO). Twitter post n. 1217043229427761152. URL: https://twitter.com/who/status/1217043229427761152 (Accessed January 6, 2022).

[31] The Straits Times. Wuhan virus has limited human-to-human transmission but could spread wider: WHO.

URL: https://www.straitstimes.com/asia/east-asia/wuhan-virus-has-limited-human-to-human-transmiss ion-but-could-spread-wider-who (Accessed January 6, 2022). 
[32] Canadian Broadcasting Corporation (CBC). 'Possible' there was limited human-to-human transmission of new coronavirus in China, WHO says. URL: https://www.cbc.ca/news/health/china-virus-who-1.5426630 (Accessed January 6, 2022).

[33] Gandhi M, Yokoe DS, Havlir DV. Asymptomatic Transmission, the Achilles' Heel of Current Strategies to Control Covid-19. N Engl J Med. 2020 May 28;382(22):2158-2160. doi: 10.1056/NEJMe2009758. Epub 2020 Apr 24. PMID: 32329972; PMCID: PMC7200054.

[34] Sah P, Fitzpatrick MC, Zimmer CF, Abdollahi E, Juden-Kelly L, Moghadas SM, Singer BH, Galvani AP. Asymptomatic SARS-CoV-2 infection: A systematic review and meta-analysis. Proc Natl Acad Sci U S A. 2021 Aug 24;118(34):e2109229118. doi: 10.1073/pnas.2109229118. PMID: 34376550; PMCID: PMC8403749.

[35] Cevik M, Kuppalli K, Kindrachuk J, Peiris M. Virology, transmission, and pathogenesis of SARS-CoV-2. BMJ. 2020 Oct 23;371:m3862. doi: 10.1136/bmj.m3862. PMID: 33097561.

[36] Reuters. WHO says new China virus could spread, it's warning all hospitals. Jan 14; 2020. URL: https://www.reuters.com/article/china-health-pneumonia-who-idUSL8N29F48F (Accessed January 6, 2022).

[37] Nebehay S. WHO says new China virus could spread, it's warning all hospitals. Reuters. Jan 14; $2020 . \quad$ URL: https://www.reuters.com/article/us-china-health-pneumonia-who-idUSKBN1ZD16J (Accessed January 6, 2022).

[38] Talic S, Shah S, Wild H, Gasevic D, Maharaj A, Ademi Z, Li X, Xu W, Mesa-Eguiagaray I, Rostron J, Theodoratou E, Zhang X, Motee A, Liew D, llic D. Effectiveness of public health measures in reducing the incidence of covid-19, SARS-CoV-2 transmission, and covid-19 mortality: systematic review and meta-analysis. BMJ. 2021 Nov 17;375:e068302. doi: 10.1136/bmj-2021-068302. Erratum in: BMJ. 2021 Dec 3;375:n2997. PMID: 34789505.

[39] Rypdal K, Bianchi FM, Rypdal M. Intervention Fatigue is the Primary Cause of Strong Secondary Waves in the COVID-19 Pandemic. Int J Environ Res Public Health. 2020 Dec 21;17(24):9592. doi: 10.3390/ijerph17249592. PMID: 33371489; PMCID: PMC7767484.

[40] Pluchino A, Biondo AE, Giuffrida N, Inturri G, Latora V, Le Moli R, Rapisarda A, Russo G, Zappalà C. A novel methodology for epidemic risk assessment of COVID-19 outbreak. Sci Rep. 2021 Mar 5;11(1):5304. doi: 10.1038/s41598-021-82310-4. Erratum in: Sci Rep. 2021 Jul 28;11(1):15719. PMID: 33674627; PMCID: PMC7935987.

[41] Centers for Disease Control and Prevention (CDC). People with Certain Medical Conditions.

URL: https://www.cdc.gov/coronavirus/2019-ncov/need-extra-precautions/people-with-medical-conditi ons.html (Accessed January 10, 2022). 
[42] Hadj Hassine I. Covid-19 vaccines and variants of concern: A review. Rev Med Virol. 2021 Nov 9:e2313. doi: 10.1002/rmv.2313. Epub ahead of print. PMID: 34755408; PMCID: PMC8646685.

[43] Huisman J, Smits J. Duration and quality of the peer review process: the author's perspective. Scientometrics. 2017;113(1):633-650. doi: 10.1007/s11192-017-2310-5. Epub 2017 Mar 9. PMID: 29056794; PMCID: PMC5629227.

[44] Elmore SA, Weston EH. Predatory Journals: What They Are and How to Avoid Them. Toxicol Pathol. 2020 Jun;48(4):607-610. doi: 10.1177/0192623320920209. Epub 2020 Apr 22. PMID: 32319351; PMCID: PMC7237319.

[45] Strinzel M, Severin A, Milzow K, Egger M. Blacklists and Whitelists To Tackle Predatory Publishing: a Cross-Sectional Comparison and Thematic Analysis. mBio. 2019 Jun 4;10(3):e00411-19. doi: 10.1128/mBio.00411-19. Erratum in: mBio. 2021 Jan 5;12(1): PMID: 31164459; PMCID: PMC6550518.

[46] Dhammi IK, Haq RU. What is indexing. Indian J Orthop. 2016 Mar-Apr;50(2):115-6. doi: 10.4103/0019-5413.177579. PMID: 27053798; PMCID: PMC4800951.

[47] Vakil C. Predatory journals: Authors and readers beware. Can Fam Physician. 2019 Feb;65(2):92-94. PMID: 30765346; PMCID: PMC6515480.

[48] Manca A, Moher D, Cugusi L, Dvir Z, Deriu F. How predatory journals leak into PubMed. CMAJ. 2018 Sep 4;190(35):E1042-E1045. doi: 10.1503/cmaj.180154. PMID: 30181150; PMCID: PMC6148641.

[49] Shen C, Björk BC. 'Predatory' open access: a longitudinal study of article volumes and market characteristics. BMC Med. 2015 Oct 1;13:230. doi: 10.1186/s12916-015-0469-2. PMID: 26423063; PMCID: PMC4589914.

[50] Sample I. Harvard University says it can't afford journal publishers' prices. The Guardian. URL:

https://www.theguardian.com/science/2012/apr/24/harvard-university-journal-publishers-prices (Accessed January 11, 2022).

[51] Ali PA, Watson R. Peer review and the publication process. Nurs Open. $2016 \mathrm{Mar}$ 16;3(4):193-202. doi: 10.1002/nop2.51. PMID: 27708830; PMCID: PMC5050543.

[52] Hope AA, Munro CL. Criticism and Judgment: A Critical Look at Scientific Peer Review. Am J Crit Care. 2019 Jul;28(4):242-245. doi: 10.4037/ajcc2019152. PMID: 31263004.

[53] Pier EL, Brauer M, Filut A, Kaatz A, Raclaw J, Nathan MJ, Ford CE, Carnes M. Low agreement among reviewers evaluating the same NIH grant applications. Proc Natl Acad Sci U 
S A. 2018 Mar 20;115(12):2952-2957. doi: 10.1073/pnas.1714379115. Epub 2018 Mar 5. PMID: 29507248; PMCID: PMC5866547.

[54] Oxman AD, Guyatt GH, Singer J, Goldsmith CH, Hutchison BG, Milner RA, Streiner DL. Agreement among reviewers of review articles. J Clin Epidemiol. 1991;44(1):91-8. doi: 10.1016/0895-4356(91)90205-n. PMID: 1824710.

[55] Anderson C, Nugent K, Peterson C. Academic Journal Retractions and the COVID-19 Pandemic. J Prim Care Community Health. 2021 Jan-Dec;12:21501327211015592. doi: 10.1177/21501327211015592. PMID: 33949228; PMCID: PMC8114243.

[56] Adler JR Jr. A new age of peer reviewed scientific journals. Surg Neurol Int. 2012;3:145. doi: 10.4103/2152-7806.103889. Epub 2012 Nov 27. PMID: 23230526; PMCID: PMC3515965.

[57] Checco A, Bracciale L, Loreti P, Pinfield S, Bianchi G. Al-assisted peer review. Humanit Soc Sci Commun. 2021;8:25. doi: 10.1057/s41599-020-00703-8.

[58] Brainard J. The $\$ 450$ question: Should journals pay peer reviewers? Science. 2021 Mar 5. doi: 10.1126/science.abh3175.

[59] Karma Credits - What are they and how to collect them? JMIR Publications Knowledge Base and Help Center. URL: https://support.jmir.org/hc/en-us/articles/115001104247-Karma-Credits-What-are-they-and-how-t o-collect-them- (Accessed January 10, 2022).

[60] Wadman M. Scientists quit journal board, protesting 'grossly irresponsible' study claiming COVID-19 vaccines kill. Science. 2021 Jul 1. doi: 10.1126/science.abk2629

[61] Rovetta A. it is ridiculous and shameful that part of the scientific community adopts the impact factor as an index of the quality of an academic journal or, worse, of the articles published in it. URL: https://www.facebook.com/alex4lp/posts/4087687737955514 (Accessed January 12, 2022).

[62] Chen T, Guestrin C. XGBoost: A Scalable Tree Boosting System. arXiv:1603.02754 (preprint). doi: 10.1145/2939672.2939785.

[63] Matosin N, Frank E, Engel M, Lum JS, Newell KA. Negativity towards negative results: a discussion of the disconnect between scientific worth and scientific culture. Dis Model Mech. 2014 Feb;7(2):171-3. doi: 10.1242/dmm.015123. PMID: 24713271; PMCID: PMC3917235.

[64] Bespalov A, Steckler T, Skolnick P. Be positive about negatives-recommendations for the publication of negative (or null) results. Eur Neuropsychopharmacol. 2019 Dec;29(12):1312-1320. doi: 10.1016/j.euroneuro.2019.10.007. 
[65] De Vrieze J. An unpublished COVID-19 paper alarmed this scientist-but he had to keep silent. Science 2021 Sep 3. doi: 10.1126/science.acx9033.

[66] van Dijk WB, Grobbee DE, de Vries MC, Groenwold RHH, van der Graaf R, Schuit E. A systematic breakdown of the levels of evidence supporting the European Society of Cardiology guidelines. Eur J Prev Cardiol. 2019 Dec;26(18):1944-1952. doi: 10.1177/2047487319868540. Epub 2019 Aug 14. PMID: 31409110; PMCID: PMC6886117.

[67] Burns PB, Rohrich RJ, Chung KC. The levels of evidence and their role in evidence-based medicine. Plast Reconstr Surg. 2011 Jul;128(1):305-310. doi: 10.1097/PRS.0b013e318219c171. PMID: 21701348; PMCID: PMC3124652.

[68] Koerber A. Is It Fake News or Is It Open Science? Science Communication in the COVID-19 Pandemic. J Bus Tech Commun. 2020 Sep 22;35(1):22-27. doi: 10.1177/1050651920958506. 